\title{
Good Housekeeping - A Panacea for Slips, Trips \& Falls Accident in the NLNG Project, Bonny
}

\author{
Mba Okechukwu Agwu ${ }^{1} \&$ Samuel Oluwadare Ajayi ${ }^{2}$ \\ ${ }^{1}$ Faculty of Management Sciences, Department of Business Administration, Niger Delta University, Wilberforce \\ Island, Nigeria \\ ${ }^{2}$ Human Resources Division, Nigeria LNG Limited, Plant Complex, Bonny Island, Rivers State, Nigeria \\ Correspondence: Dr. Mba Okechukwu Agwu, Faculty of Management Sciences, Department of Business \\ Administration, Niger Delta University, Wilberforce Island, Bayelsa State, Nigeria. Tel: 234-803-793-6191. E-mail: \\ mbaagwu38@yahoo.com
}

Received: April 24, 2014

Accepted: June 4, 2014

Online Published: June 22, 2014

doi:10.5430/ijba.v5n4p12

URL: http://dx.doi.org/10.5430/ijba.v5n4p12

\begin{abstract}
The paper discussed good housekeeping- a panacea for slips, trips \& falls (STF) accident in the NLNG project Bonny. Good housekeeping entails cleaning and orderly arrangement of materials in the workplace. The study assumes that good housekeeping practices will eliminate workplace clutter (unsafe condition) which is the common cause of STF accident and make the workplace neat, comfortable and pleasant. The research question ascertained the extent at which elimination of workplace clutter (unsafe condition) and reduction of STF accident rate is influenced by the implementation of good housekeeping programme in the NLNG project Bonny. A descriptive research design was used in conducting the study; using questionnaire administered on 384 randomly selected employees of the ten NLNG construction companies in Bonny Island. Data collected were analyzed using descriptive statistics. The results indicated that implementation of good housekeeping programme to a large extent eliminated workplace clutter and reduced STF accident rate in the NLNG project Bonny. The study therefore recommends among others: management leadership and commitment on good housekeeping, regular housekeeping audits, regular training of employees on good housekeeping techniques, introduction of good housekeeping incentives and encouragement of good housekeeping culture among the workforce.
\end{abstract}

Keywords: good housekeeping, workplace clutter, slips, trips \& falls, NLNG project Bonny

\section{Introduction}

The Nigeria Liquefied Natural Gas (NLNG) company was incorporated in May 17, 1989, to produce and export liquefied natural gas (LNG) and natural gas liquids (NGLs) from the natural gas resources of the country (NLNG, 2013). To achieve this objective, a contract for the construction of a gas processing plant in Bonny Island was awarded in December, 1995 with the incorporation of good housekeeping programme into the contract document to ensure zero slips, trips \&falls accident in the project execution in accordance with the provisions of the Mineral Oils (Safety) Regulations(1997).

Good housekeeping is an accident preventive progamme designed to encourage workers to clean and properly arrange materials in their workplace. Its focus is on creating awareness on those neglected unsafe work conditions that may cause slips, trips and falls (STF) accident, since STF accounts for $33 \%$ of all reported major injuries at work. Almost one in every five work related accident is associated with STF (Leamon \& Murphy 1995). Over 13.5 million people are injured every year in STF related accident (Hanson, 2012). Good housekeeping is not just cleanliness. It encompasses: orderly arrangement of work areas; keeping halls and floors free of slip and trip hazards and removal of waste materials/other fire hazards from work areas. It also requires paying attention to: workplace layout, aisle marking and maintenance of storage facilities.

Poor housekeeping may result in: slipping on greasy, wet or dirty surfaces; tripping over loose objects on floors, stairs and platforms; being hit by falling objects and striking against poorly stacked items or misplaced material. To avoid these hazards, good housekeeping must be maintained in a workplace on daily basis. Although this requires a great deal of effort, the benefits far outweighs the costs. The benefits of good housekeeping include: • improved 
employees' morale $\bullet$ fewer STF accidents $\bullet$ less janitorial work $\bullet$ improved control of tools and materials $\bullet$ decreased fire hazards $\bullet$ better hygienic conditions $\cdot$ reduced exposure to hazardous substances and $\cdot$ more effective use of space.

The researchers adopted a management/employee partnership approach to good housekeeping with emphasis on collective management/employees' efforts in the eradication of workplace clutter. The study is confined to the field workers (supervisors, foremen and workmen) of the ten construction companies that are executing the NLNG project Bonny.

\subsection{Problem Statement}

With an average workforce of 9,566 persons, the NLNG project Bonny has recorded an average of 40 slips, 30 trips and 10 falls per annum, since its commencement in 1996(NLNG,2013). This figure is relatively insignificant when compared to the size of the workforce and the general construction industry accident statistics. STF accidents usually results in the company incurring unexpected expenses such as: payment of medical bills of the accident victim, payment of compensation for disability, payment of victim's disability services, payment of wages while victim is hospitalized, payment of burial expenses in case of death, payment of fines to the government and payment of litigation expenses in case of court action.

Organizations with high frequency of STF accidents are generally considered unsafe and risky, hence they usually experience high rate of labour turnover, loss of future contracts, loss of reputation, loss of productivity, loss of man-hours, loss of machine-hours and payment of high insurance premium. These losses can be prevented through the eradication of workplace clutter via good housekeeping programme that is management/employees driven.

\subsection{Research Objectives}

The research objectives are as follows:

1). To ascertain the extent at which elimination of workplace clutter (unsafe condition) is influenced by the implementation of good housekeeping programme in the NLNG project Bonny.

2). To find out the extent at which reduction of slips, trips \& falls accident rate is influenced by the implementation of good housekeeping programme in the NLNG project Bonny.

\subsection{Research Questions}

The inadequacies associated with earlier industrial housekeeping methods, which were either management or employee driven, necessitated the development of the management/employees partnership approach to good housekeeping in the construction industry thus prompting the following research questions:

1). To what extent is elimination of workplace clutter (unsafe condition) influenced by the implementation of good housekeeping programme in the NLNG project Bonny?

2). To what extent are slips, trips \&falls accident rate reduction influenced by the implementation of good housekeeping programme in the NLNG project Bonny?

\subsection{Research Hypotheses}

Considering the aforementioned research questions, the following null hypotheses are hereby postulated:

$1 \mathrm{H}_{\mathrm{O}}$ : Elimination of workplace clutter (unsafe condition) is not influenced by the implementation of good housekeeping programme in the NLNG project Bonny.

$2 \mathrm{H}_{\mathrm{O}}$ : Slips, trips \&falls accident rate reduction is not influenced by the implementation of good housekeeping programme in the NLNG project Bonny.

\subsection{Literature Review}

Orderliness is the first priority in the prevention of slips, trips \& falls accident in the workplace. According to Kemmlert \& Lundholm (2001), every fourth STF accident could be prevented if objects and spillages on floor surfaces were removed or cleaned up. Ray, Purswell \& Bowen (1993), found an inverse relationship between good housekeeping and overall injury rate for a farm machinery manufacturing plant. This suggests that programmes aimed at increasing good housekeeping should be associated with a reduction in workplace injuries. Davis (1983) observed that a $35 \%$ increase in good housekeeping was associated with a reduction of STF accidents by $54 \%$.

Furthermore, Salminen\& Saari (1995) found in an experiment carried out in a Finnish shipyard that reduction in STF accidents $(70-90 \%)$ was as a result of improvements in housekeeping. They believed that the experiment encouraged workers to take care of all workplace hazards, not just those they were trained to target. Thus in targeting a greater 
variety of workplace hazards, the overall STF accident rate decreased more than anticipated. Laitinen et al (1997) conducted a housekeeping study in a Finnish metal workshop using an observation checklist in which each item on the checklist was scored as correct or incorrect. After establishing a baseline level of housekeeping, the mean housekeeping index increased from $57 \%$ to $89 \%$. Furthermore, sickness absence decreased from $12.8 \%$ of the total working hours in 1991 to $9.9 \%$ in 1994 . These studies appear to demonstrate that good housekeeping practice is a sound method for reducing STF hazards and consequently reduce STF injuries.

Quintana (1999) carried out a task-delineated safety (TDS) method for the control of STF hazards at a used clothes-sorting facility and reported that the cost of STFs for the company at the time was reduced by approximately by two million US dollars than in the previous three years. In the study, two matched areas were chosen. Employees from one area were given instruction during safety meetings on the specific STF hazards they were required to monitor and control. The underlying human and economic consequences for not removing hazards in relation to the company and employees were also explained. Each employee was assigned an equally divided and specific area of responsibility. It was found that the TDS methodology out-performed the normal approach with respect to the number of hazards observed. By decreasing the number of hazards observed, the probability of STF incident occurring was also diminished.

Saari (1987) conducted a study relating to the management of good housekeeping by feedback. The study was conducted in a margarine factory. The factory was divided into observable areas and an observation form was compiled. Examples of observations included: 'gangways are kept free from materials and other objects', 'empty pallets are returned to stores and stacked one on top of another' and 'grease, water and litter are removed from the floor'. These items were then being scored as correct or incorrect. The housekeeping index rose from an initial baseline level of between 50 and 70 to more than 80 as a result of the elimination of workplace clutter. Saari considers the use of positive feedback (via tracking of housekeeping levels) as a promising approach to the management of human behaviour.

Lehane and Stubbs (2001) found that managers in the service industries were most likely to place causal responsibility for STF on the accident subject. As a result, managers were less likely to implement any remedial actions involving alterations to the environment, plant or work systems. Instead they attempted to modify worker behaviour. Managers also seemed to place causal responsibility with the accident subject to divert any criticism away from potential management failure. Bentley and Haslam (2001) found that delivery office managers from post offices with low STF accident rates displayed the following characteristics: better quality of safety communication (discussion with delivery officers), dealing with STF hazards reported on delivery walks and better accident investigation and remedial action.

\subsection{Conceptual Framework}

Good housekeeping is an accident preventive progamme designed to encourage workers to clean and properly arrange materials in their workplace. It means keeping away all unnecessary items and keeping all necessary items in their proper places (IAPA, 2006). Keeping work areas orderly and clean can make work safer, healthier and easier. Every employee has a responsibility to ensure good housekeeping in all phases of the job. It is a lot easier to clean up as you work instead of waiting for the end of shift. We can have a clean and STF accident-free workplace if everyone cooperates.

Good housekeeping at work benefits both employers and employees alike. It can: •eliminate clutter which is a common cause of STF accident; - reduce the chances of harmful materials (dusts \&vapours) entering the body; • improve productivity; $\cdot$ improve company's image, $\bullet$ minimize inventory; $\bullet$ help the company to make the best use of its space and $\cdot$ make the workplace neat, comfortable and pleasant. The signs of poor housekeeping that may be recognized in every workplace include: $\bullet$ cluttered and poorly arranged work areas; $\bullet$ untidy or dangerous storage of materials; • dusty and dirty floors; • blocked or cluttered aisles and exits; $\bullet$ littered tools and equipment; $\bullet$ broken containers and damaged materials; $\bullet$ overflowing waste bins; $\bullet$ spills and leaks (IAPA, 2006).

\subsection{Legal Framework}

Regulation 9 of the UK Workplace (Health, Safety \& Welfare) Regulations 1992 stipulates that workplaces should be kept suitably clean. It also stipulates that waste materials and rubbish should be kept to a minimum and stored in suitable containers. Regulation 12 stipulates that every floor and surface of all traffic routes within a workplace must be suitably constructed and should be kept as free as possible from any obstructions that could cause slips, trips or falls. Where surfaces are likely to become wet, either through the work process or because of spillage, a suitable system of controlling the risk of slipping must be in place - either through drainage, a cleaning-up system or slip-resistant coating. 
Regulation 13 stipulates that employers should securely cover or fence any tank or pit that possesses the risk of people falling into it.

Section 20 of the Nigerian Factory Act (1990) stipulates that factory owners should: • clean up spills promptly according to procedures; $\bullet$ keep oily rags and hazardous materials in covered and marked metal containers; • ensure that exits and aisles are clear of obstructions to allow easy evacuation of the building; •place all trash and scrap in proper containers; •store equipment and materials in their assigned location;•clean air vents and filters to maintain ventilation efficiency; •ensure that boxes, drums and piles are located on a firm foundation and properly stacked; -clean up tools and unused materials after finishing a job or before leaving the job site; • minimize fire hazards by keeping their workplace free of accumulated combustible materials and waste; •bundle hoses and cables when not in use; •place empty containers and pallets in designated locations; •keep only enough combustible materials at job site for job at hand.

OSHA regulation 29CFR stipulates that every employee has a personal responsibility to: $\bullet$ keep his or her work area neat, clean and safe; $\bullet$ keep every walkway or stairs clear and uncluttered; $\bullet$ return tools, materials or supplies to its assigned place when not in use; $\bullet$ report anything that is broken or not functioning properly; $\bullet$ report any trip hazards right away; $\bullet$ follow up on any safety violation noticed; $\bullet$ read and follow MSDS.

\subsection{Theoretical Framework}

This research is based on the accident root causes tracing model (ARCTM) of Abdelhamid \& Everett (2000) which states that occupational slips, trips \&falls accident will occur as a result of one or more of the following three root causes:(1) Failing to identify an unsafe condition that existed before an activity started or that developed after an activity has started. (2) Deciding to proceed with a work activity after the worker has identified an existing unsafe condition. (3) Deciding to act unsafely regardless of initial conditions of the work environment. The ARCTM model attempts to direct the attention of the STF accident investigator to the conditions that existed at the time of the accident and antecedent human behavior.

In addition, the model emphasizes the need to determine how unsafe conditions existed before or developed after an activity has started and asserts that these unsafe conditions arise from four causes: (1) management actions/inactions; (2) unsafe acts of a worker or coworker; (3) non-human-related event(s) and (4) unsafe condition associated with initial construction site conditions. Thus, ARCTM acknowledges the possible contribution of both management and labour to the STF accident process. This perspective helps in better explaining STF accidents on construction sites and in identifying areas where preventive efforts should be directed, so that labour and management may provide more effective measures for preventing STF accident occurrence.

Unsafe conditions, workers response to unsafe conditions and workers unsafe acts are the cornerstones of the ARCTM model. An unsafe condition is a situation in which either the physical layout of the workplace or the materials/equipment status is in violation of contemporary safety standards. Unsafe conditions are mentioned in almost every accident causation model as the main cause of an accident. The worker's decision is either to act safely and discontinue the work until the unsafe condition is corrected or to take a chance (act unsafely) and continue working. The reasons behind failing to identify the unsafe condition or the decision to act unsafely after identifying an unsafe condition should be thoroughly investigated by management. It is important to note that workers may commit unsafe acts regardless of the conditions of the workplace, hence there is need to investigate why workers act unsafely.

\subsection{Good Housekeeping Methodology}

According to Workplace Safety \& Prevention Services (2011), some good housekeeping practices include: $\bullet$ Follow safe work procedures and the requirements of the law. $\bullet$ Keep work areas clean. $\bullet$ Keep aisles clear. $\bullet$ Keep exits and entrances clear. $\cdot$ Keep floors clean, dry and in good condition. $\bullet$ Vacuum or wet sweep dusty areas frequently. $\bullet$ Stack and store items safely. -Store all work materials (paper products, flammable liquids, etc.) in approved, clearly labelled containers in designated storage areas only. $\bullet$ Use proper waste containers. $\bullet$ Keep sprinklers, fire alarms and fire extinguishers clear. $\bullet$ Clean up spills and leaks of any type quickly and properly. $\bullet^{\bullet}$ Clean and store tools, items and equipment properly. $\bullet$ Fix or report broken or damaged tools, equipment, etc. $\bullet$ Keep lighting sources clean and clear. -Follow maintenance requirements.

Good housekeeping requires effort and teamwork and may be improved in the following ways: $\bullet$ Set housekeeping standards and ensure they are clear, objective and attainable. $\bullet$ Standards should make work easier, safer and healthier. -It is best to involve employees when setting standards. $\bullet$ Measure how well the standards are met. $\bullet$ Use checklists to systematically measure good housekeeping compliance. $•$ Provide positive feedback by letting employees know how 
well they are doing and how to improve. Encourage good housekeeping as a way of life - not just a special activity when visitors are coming (Workplace Safety \& Prevention Services, 2011).

According to Institute of Safety Professionals of Nigeria (2012), the five steps to good housekeeping include: Sort, Store, Shine, Standardize and Sustain. Sort implies getting rid of unnecessary items i.e. looking around the work area to identify and remove unnecessary items. Store implies a place for everything and everything in its place i.e. arranging necessary items in a proper order so that they can easily be picked up for use. Shine implies continuous cleaning of workplace and equipment as soon as possible instead of waiting for the end of shift. Standardize implies setting standards for housekeeping i.e. developing cleaning schedules, methods and checklists and assigning responsibilities to persons. Sustain implies training employees to follow good housekeeping procedures and inculcating it as a corporate culture i.e. monitoring performance to ensure standards are maintained.

\section{Research Methodology}

The study is confined to the field workers (supervisors, foremen and workmen) of the ten construction companies that are executing the NLNG project Bonny. A cross-sectional survey of the sample respondents was used in generating the primary data required for the study. The population of study consists of 9,566workers comprising of three categories of field workers (280 supervisors, 830 foremen and 8,456workmen) in the ten construction companies executing the NLNG project Bonny. A sample of 384 workers (11supervisors, 33 foremen and 340 workmen) determined at 5\% level of significance for sample error, using Yamane(1964) formula, was selected using stratified random sampling method for the purpose of questionnaire administration. The sample respondents were selected using shuffling of cards method (without replacement) in which all the names of the three categories of field workers were each separately written on small cards and the name on the topmost of each of the three group of cards was selected each time, the cards were shuffled until all the sample respondents were selected.

The questionnaire was designed to elicit the unbiased opinions of the three categories of field workers in the ten NLNG construction companies using a three-point Likert type scale. Data collected were analyzed using descriptive statistics. A total of 384 copies of the questionnaire were administered, 5 were cancelled, 4 were not returned while $375(98 \%)$ were used for the analysis.

\subsection{Calculation of Sample Size}

The sample size was determined from a population of 9,566 field workers of the ten construction companies that are executing the NLNG project bonny using Yamane (1964) formula for sample size determination thus:

$$
\mathrm{n}=\frac{\mathrm{N}}{1+\mathrm{N}(\mathrm{e})^{2}}
$$

Where: $\mathrm{n}=$ sample size, $\mathrm{N}=$ population size, $\mathrm{e}=$ level of significance/sample error factor.

$$
\mathrm{n}=\frac{9,566}{1+9,566(0.05)^{2}} \quad=\frac{9,566}{24.915} \quad=383.95=384
$$

\section{Results and Discussions}

\subsection{Distribution of Sample Respondents}

The distribution of sample respondents among the three categories of field workers in the ten NLNG construction

\begin{tabular}{|c|c|c|c|c|c|}
\hline S/No & Name of Company & Supervisors & Foremen & Workmen & $\begin{array}{c}\text { Total Number of } \\
\text { Sample } \\
\text { Respondents }\end{array}$ \\
\hline 1. & Julius Berger Nigeria PLC & 1 & 4 & 54 & 59 \\
\hline 2. & $\begin{array}{c}\text { Daewoo Engineering and } \\
\text { Electrical Construction } \\
\text { Company }\end{array}$ & 1 & 4 & 50 & 55 \\
\hline 3. & Fougerolle Nigeria Limited & 1 & 3 & 35 & 39 \\
\hline 4. & $\begin{array}{c}\text { Cimimontubi Nigeria } \\
\text { Limited }\end{array}$ & 1 & 3 & 30 & 34 \\
\hline
\end{tabular}
companies is as shown in table 1 below:

Table 1. Distribution of sample respondents among the ten NLNG construction companies 


\begin{tabular}{lccccc}
\hline 5. & DBN Nigeria Limited & 1 & 3 & 30 & 34 \\
\hline 6. & Spibat Nigeria Limited & 1 & 3 & 35 & 39 \\
\hline 7. & Bouygues Nigeria Limited & 1 & 3 & 21 & 25 \\
\hline 8. & $\begin{array}{c}\text { Chicago Bridge and Iron } \\
\text { Company Limited }\end{array}$ & 1 & 3 & 28 & 32 \\
\hline 9. & Dumez Nigeria Limited & 1 & 3 & 30 & 34 \\
\hline 10. & Etco Nigeria Limited & 1 & 3 & 20 & 24 \\
\hline & $\begin{array}{c}\text { Total Number of Sample } \\
\text { Respondents }\end{array}$ & 10 & 32 & 333 & 375 \\
\hline
\end{tabular}

Source: Field Research, 2014.

\subsection{Distribution of Responses on Research Questions}

The sample responses of the three categories of field workers (supervisors, foremen and workmen) in the ten NLNG construction companies is as summarized in table 2 below:

Table 2. Summary of sample responses on research questions

\begin{tabular}{|c|c|c|c|c|c|}
\hline $\mathrm{S} / \mathrm{No}$ & Research Questions & $\begin{array}{l}\text { Large } \\
\text { Extent }\end{array}$ & $\begin{array}{l}\text { Mild } \\
\text { Extent }\end{array}$ & $\begin{array}{l}\text { Poor } \\
\text { Extent }\end{array}$ & $\begin{array}{l}\text { Total } \\
\text { Responses }\end{array}$ \\
\hline 1. & $\begin{array}{l}\text { To what extent does your company implement } \\
\text { good housekeeping programme in the execution of } \\
\text { the NLNG project Bonny? }\end{array}$ & 297 & 59 & 19 & 375 \\
\hline 2. & $\begin{array}{l}\text { To what extent has the implementation of good } \\
\text { housekeeping programme contributed to the } \\
\text { elimination of workplace clutter (unsafe condition) } \\
\text { in your company? }\end{array}$ & 248 & 98 & 29 & 375 \\
\hline 3. & $\begin{array}{l}\text { To what extent has the implementation of good } \\
\text { housekeeping programme contributed to the } \\
\text { reduction of slips, trips \& falls accident rate in } \\
\text { your company? }\end{array}$ & 222 & 114 & 39 & 375 \\
\hline 4. & $\begin{array}{l}\text { To what extent is elimination of workplace clutter } \\
\text { (unsafe condition) influenced by the } \\
\text { implementation of good housekeeping programme } \\
\text { in the NLNG project Bonny? }\end{array}$ & 243 & 108 & 24 & 375 \\
\hline 5. & $\begin{array}{l}\text { To what extent are reduced slips, trips \& falls } \\
\text { accident rate influenced by the implementation of } \\
\text { good housekeeping programme in the NLNG } \\
\text { project Bonny? }\end{array}$ & 237 & 99 & 39 & 375 \\
\hline
\end{tabular}

Source: Field Research, 2014.

Table 2 shows that $297(79.20 \%$ ) of the sample respondents were of the opinion that their company to a large extent implements good housekeeping programme in the execution of the NLNG project Bonny, 59(15.73\%) respondents expressed a mild extent view while 19(5.07 \%) respondents expressed a poor extent view of their company's implementation of good housekeeping programme in the execution of the NLNG project Bonny. 248 (66.13\%)respondents were of the view that implementation of good housekeeping programme has to a large extent contributed to the elimination of workplace clutter (unsafe condition)in their company,98 $(26.13 \%)$ respondents expressed a mild extent view while 29(7.73\%) respondents expressed a poor extent view. $222(59.20 \%)$ respondents were of the view that their company's implementation of good housekeeping programme has contributed to the reduction of slips, trips \&falls accident rate in their project execution, $114(30.40 \%)$ respondents expressed a mild extent view while 39(10.40\%) respondents expressed a poor extent view. $243(64.80 \%)$ respondents were of the view that elimination of workplace clutter (unsafe condition) in their company was to a large extent influenced by the implementation of good housekeeping programme in their project execution, $108(28.80 \%)$ respondents expressed a mild extent view while 24(6.40\%)were of the opinion that elimination of workplace clutter (unsafe condition) was to a poor extent influenced by their company's implementation of good housekeeping programme in their project execution. 237 (63.20\%)respondents were of the opinion that reduced slips, trips \& falls accident rate in their company was to a large extent influenced by the implementation of good housekeeping programme in their project execution,99 $(26.40 \%)$ respondents expressed a mild extent view while $39(10.40 \%)$ respondents were of the 
view that reduced slips, trips \&falls accident rate in their company was to a poor extent influenced by the implementation of good housekeeping programme in their project execution.

The computation of the observed and expected frequencies for questions 4 and 5 are as shown in Tables 3 and 4 below:

Table 3. Observed and expected frequencies of question number 4

\begin{tabular}{lllll}
\hline Category & of & \multicolumn{2}{l}{ Responses Provided } & \\
\cline { 2 - 5 } Respondents/Workers & Large extent & Mild extent & Poor extent & Total \\
\hline Supervisors & $8(7.13)$ & $2(3.17)$ & $1(0.70)$ & 11 \\
\hline Foremen & $12(20.09)$ & $9(8.93)$ & $10(1.98)$ & 31 \\
\hline Workmen & $223(215.78)$ & $97(95.90)$ & $13(21.31)$ & 333 \\
\hline Total & 243 & 108 & 24 & 375 \\
\hline
\end{tabular}

Source: Field Research, 2014.

Table 4. Observed and expected frequencies of question number 5

\begin{tabular}{lllll}
\hline Category & of & \multicolumn{2}{l}{ Responses Provided } & \\
\cline { 2 - 5 } Respondents/Workers & Large extent & Mild extent & Poor extent & Total \\
\hline Supervisors & $9(6.95)$ & $1(2.90)$ & $1(1.14)$ & 11 \\
\hline Foremen & $11(20.22)$ & $7(8.45)$ & $14(3.33)$ & 32 \\
\hline Workmen & $217(209.82)$ & $91(87.65)$ & $24(34.53)$ & 332 \\
\hline Total & 237 & 99 & 39 & 375 \\
\hline
\end{tabular}

Source: Field Research, 2014.

\subsection{Test of Hypotheses}

\subsubsection{Test of the First Hypothesis}

(i) $\mathbf{H}_{\mathbf{O}}$ : Elimination of workplace clutter (unsafe condition) is not influenced by the implementation of good housekeeping programme in the NLNG project Bonny.

$\mathbf{H}_{1:}$ Elimination of workplace clutter (unsafe condition) is influenced by the implementation of good housekeeping programme in the NLNG project Bonny.

(ii) $\alpha=0.05$

(iii) Degree of Freedom (df) $=(\mathrm{r}-1)(\mathrm{c}-1=(3-1)(3-1)=4$

(iv) Chi- square critical table value $\left(\chi_{\mathrm{t}}^{2}\right)=\chi_{0.05}^{2}=9.49$

Table 5. Computation of Chi-square critical computed value $\left(\chi_{c}^{2}\right)$ from Table 3

\begin{tabular}{lllll}
\hline Fo & Fe & $(\mathrm{Fo}-\mathrm{Fe})$ & $(\mathrm{Fo}-\mathrm{Fe}) / \mathrm{Fe}$ & $(\mathrm{Fo}-\mathrm{Fe})^{2} / \mathrm{Fe}$ \\
\hline 8 & 7.13 & 0.87 & 0.1220 & 0.1062 \\
\hline 2 & 3.17 & -1.17 & -0.3691 & 0.4318 \\
\hline 1 & 0.70 & 0.30 & 0.4286 & 0.1286 \\
\hline 12 & 20.09 & -8.09 & -0.4027 & 3.2577 \\
\hline 9 & 8.93 & 0.07 & 0.0078 & 0.0005 \\
\hline 10 & 1.98 & 8.02 & 4.0505 & 32.4851 \\
\hline 223 & 215.78 & 7.22 & 0.0335 & 0.2416 \\
\hline 97 & 95.90 & 1.10 & 0.0115 & 0.0126 \\
\hline 13 & 21.31 & -8.31 & -0.3900 & 3.2405 \\
\hline
\end{tabular}

(vi) Decision Rule: Reject $\mathbf{H}_{0}$ if $\chi^{2}{ }_{\mathrm{c}}>\chi_{\mathrm{t}}^{2}$, Accept $\mathbf{H}_{0}$ if $\chi^{2}{ }_{\mathrm{c}}<\chi_{\mathrm{t}}^{2}$

Since $\chi^{2}{ }_{\mathrm{c}}>\chi_{\mathrm{t}}^{2}$ i.e. 39.9046>9.49, we reject the null hypothesis and accept the alternative hypothesis that elimination of workplace clutter (unsafe condition) is influenced by the implementation of good housekeeping programme in the NLNG project Bonny. This is buttressed by the research findings of Kemmlert \& Lundholm (2001), in which they found that every fourth STF accident could be prevented if objects and spillages on floor surfaces were removed or cleaned up. This is also supported by the research findings of Saari (1987) relating to the management of good housekeeping by feedback conducted in a margarine factory, in which he observed that the housekeeping index rose from an initial baseline level of between 50 and 70 to more than 80 as a result of the elimination of workplace clutter. 


\subsubsection{Test of the Second Hypothesis}

(i) $\mathbf{H}_{\mathbf{O}}$ : Slips, trips \&falls accident rate reduction is not influenced by the implementation of good housekeeping programme in the NLNG project Bonny.

$\mathbf{H}_{1:}$ Slips, trips \&falls accident rate reduction is influenced by the implementation of good housekeeping programme in the NLNG project Bonny.

(ii) $\alpha=0.05$

(iii) Degree of Freedom (df) $=(\mathrm{r}-1)(\mathrm{c}-1=(3-1)(3-1)=4$

(iv) Chi- square critical table value $\left(\chi_{t}^{2}\right)=\chi_{0.05}^{2}=9.49$

Table 6. Computation of Chi-square critical computed value $\left(\chi_{c}^{2}\right)$ from Table 4

\begin{tabular}{lllll}
\hline Fo & Fe & $(\mathrm{Fo}-\mathrm{Fe})$ & $(\mathrm{Fo}-\mathrm{Fe}) / \mathrm{Fe}$ & $(\mathrm{Fo}-\mathrm{Fe})^{2} / \mathrm{Fe}$ \\
\hline 9 & 6.95 & 2.05 & 0.2950 & 0.6047 \\
\hline 1 & 2.90 & -1.90 & -0.6552 & 1.2448 \\
\hline 1 & 1.14 & -0.14 & -0.1228 & 0.0172 \\
\hline 11 & 20.22 & -9.22 & -0.4560 & 4.2042 \\
\hline 7 & 8.45 & -1.45 & -0.1716 & 0.2488 \\
\hline 14 & 3.33 & 10.67 & 3.2042 & 34.1889 \\
\hline 217 & 209.82 & 7.18 & 0.0342 & 0.2457 \\
\hline 91 & 87.65 & 3.35 & 0.0382 & 0.1280 \\
\hline 24 & 34.53 & -10.53 & -0.3050 & 3.2111 \\
\hline
\end{tabular}

(vi) Decision Rule: Reject $H_{0:}$ if $\chi_{\mathrm{c}}^{2}>\chi_{\mathrm{t}}^{2}$, Accept $\mathrm{H}_{0}$ if $\chi_{\mathrm{c}}^{2}<\chi_{\mathrm{t}}^{2}$

Since $\chi_{\mathrm{c}}^{2}>\chi_{\mathrm{t}}^{2}$ i.e. 44.0934>9.49, we reject the null hypothesis and accept the alternative hypothesis that slips, trips \&falls accident rate reduction is influenced by the implementation of good housekeeping programme in the NLNG project Bonny. This is buttressed by the research findings of Salminen\& Saari (1995) in an experiment carried out in a Finnish shipyard in which they found that reduction in STF accidents rate (70-90\%) was as a result of improvements in housekeeping. They believed that the experiment encouraged workers to take care of all workplace hazards, not just those they were trained to target. Also, Davis (1983) observed that a $35 \%$ increase in good housekeeping was associated with a reduction of STF accidents by $54 \%$.

\section{Conclusion and Recommendations}

The paper discussed good housekeeping- a panacea for slips, trips \& falls (STF) accident in the NLNG project Bonny. The study assumes that good housekeeping practices will eliminate workplace clutter (unsafe condition) which is the common cause of STF accident and make the workplace neat, comfortable and pleasant. The major findings of the study are as follows:

- Good housekeeping programme is implemented by the ten construction companies in the execution the NLNG project Bonny.

* Elimination of workplace clutter (unsafe condition) is influenced by the implementation of good housekeeping programme in the NLNG project Bonny.

* Slips, trips \&falls accident rate reduction is influenced by the implementation of good housekeeping programme in the NLNG project Bonny.

From the findings of this research, it is suggested that the management of the ten construction companies executing the NLNG project Bonny should take the following measures to sustain the prevailing high standard of good housekeeping in the project:

1). Management leadership and commitment: Top management of the construction companies should exhibit exemplary leadership and commitment in the implementation of good housekeeping programme. They should be in the fore front in driving good housekeeping so as to ensure subordinates compliance.

2). Regular housekeeping audits: The management of the construction companies' should carry out regular housekeeping audits of their work areas to ensure employees' compliance with stipulated housekeeping standards.

3). Regular training of employees on good housekeeping techniques: The management of the NLNG construction companies should ensure a regular training for employees to enhance their housekeeping performance. 
4). Introduction of good housekeeping incentives: The management of the of the NLNG construction companies should introduce good housekeeping incentives for the workforce to elicit and sustain their commitment to good housekeeping practices.

5). Entrenchment of good housekeeping culture among the workforce: The management of the NLNG construction companies should accord good housekeeping first priority in the project execution to ensure that the workforce imbibes it as a safety culture in their day to day activities.

\section{Acknowledgements}

The authors express their gratitude to the management and staff of the ten construction companies' involved in the execution of the NLNG project Bonny for their co-operation and support in carrying out this research, especially those that completed and returned the research questionnaire.

\section{References}

Abdelhamid, T.S., \& Everett, J.G. (2000). Identifying Root Causes of Construction Accidents. Journal of Construction Engineering and Management, 126(I).

Bentley, T.A., \& Haslam, R. A. (2001). A comparison of safety practices used by managers of high and low accident rate postal delivery offices. Safety Science, 37, 19-37.

Davis, P. R. (1983). Human factors contributing to slips, trips and falls. Ergonomics, 26, 51-59.

Federal Government of Nigeria. Factory Act. (1990). Official Gazette, June/July. Lagos: Government Press, 65(1), 285-302.

Federal Government of Nigeria. Mineral Oils (Safety) Regulations. (1997). Official Gazette June/July. Lagos: Government Press, 75(1), 346-372.

Hanson, G. (2012). Preventing Slips, Trips and Falls. American Safety \& Health Management Consultants, Inc.

Industrial Accident Prevention Association. (2006). Housekeeping at Work. A health and safety guideline for your workplace. Retrieved from website:www.iapa.ca

Institute of Safety Professionals of Nigeria. (2012). General HSE Training Manual. Port- Harcourt: Dominion Publishers.

Kemmlert, K., \& Lundholm, L. (2001). Slips, trips and falls in different work groups - with reference to age and from a preventive perspective. Applied Ergonomics, 32, 149-153.

Laitinen, H., Saari, J., \& Kuusela, J. (1997). Initiating an innovative change process for improved working conditions and ergonomics with participation and performance feedback: A case study in an engineering workshop. International Journal of Industrial Ergonomics, 19, 299-305.

Leamon, T. B., \& Murphy, P. L. (1995). Occupational slips and falls: more than a trivial problem. Ergonomics, 38, 487-498.

Lehane, P., \& Stubbs, D. (2001). The perceptions of managers and accident subjects in the service industries towards slip and trip prevention. Applied Ergonomics, 32, 119-226.

NLNG. (2013). Facts and Figures on NLNG. Lagos: NLNG Public and Government Affairs Department, 2(1), 37-52.

Quintana, R. (1999). A task-delineated safety approach for slip, trip and fall hazards. Safety Science, 33, 31-45.

Ray, P. S., Purswell, J. L., \& Bowen, D. (1993). Behavioural safety program: Creating a new corporate culture. International Journal of Industrial Ergonomics, 12, 193-198.

Saari, J. (1987). Management of housekeeping by feedback. Ergonomics, 30, 313-317.

Salminen, S., \& Saari, J. (1995). Measures to improve safety and productivity simultaneously. International Journal of Ergonomics, 15, 261-269.

The Workplace (Health, Safety \& Welfare) Regulations. (1992). Approved Code of Practice and guidance. London: HMSO.

Workplace Safety \& Prevention Services. (2011). Good Housekeeping at Work. Health and Safety Ontario. 1877 494 WSPS (9777) | $9056141400 \mid$. Retrieved from www.wsps.ca

Yamane, T. (1964). Statistics: An Introduction Analysis (3rd ed.). New York: Harper and Row Publishers. 